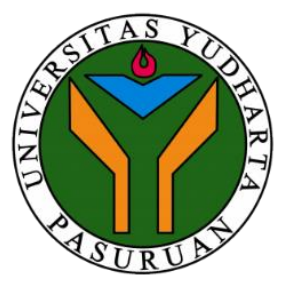

\title{
Implementasi Analisa Semantik Pada Webdriver Untuk Otomatisasi Scraping Profil Pengguna Facebook
}

\author{
Maulidiansyah ${ }^{1}$, Zainal Arifin ${ }^{2}$ \\ ${ }^{I}$ Teknologi Informasi, Universitas Nurul Jadid, Probolinggo, Indonesia \\ ${ }^{2}$ Teknologi Informasi, Universitas Nurul Jadid, Probolinggo, Indonesia \\ email:" maulid@unuja.com, ${ }^{2}$ zainal@unuja.ac.id
}

\begin{tabular}{l}
\hline INFO ARTIKEL \\
\hline Sejarah Artikel: \\
Diterima 6 Mei 2020 \\
Direvisi - \\
Disetujui 07 Desember 2020 \\
Dipublikasi 17 Desember 2020 \\
\hline Katakunci: \\
Analisa Semantik \\
Webdriver \\
Facebook Bot
\end{tabular}

\begin{abstract}
ABSTRAK
Penelitian ini membahas tentang implementasi Analisa semantik pada webdriver untuk mendapatkan data profil pengguna facebook secara otomatis. Pada era digital ini, data adalah sesuatu yang sangat berharga. Hal ini dikarenakan data dapat di olah menjadi pengetahuan baru yang bisa digunakan dalam semua lini kehidupan seperti pendidikan, ekonomi, bisnis dan lain-lain. Facebook adalah salah satu tempat penyimpanan data dalam jumlah besar. Hanya saja tidak mudah mendapatkan data dari Facebook. Dibutuhkan sebuah teknik yang bisa digunakan oleh sebuah bot untuk bisa menjelajah halaman Facebook, mengambil data profil pengguna dan mengelompokkannya berdasarkan kategori profil. Teknik tersebut adalah membuat bot dari Webdriver dengan mengimplementasikan analisa semantik.

Tahapan proses dalam penelitian ini adalah : Memahami struktur HTML pada halaman Facebook untuk mengetahui pola data profil pada Facebook. Kemudian Bot akan dikembangkan agar bisa membuka halaman profil pengguna, mengambil data profil dan kemudian menganalisanya berdasarkan pola pada struktur HTML halaman Facebook. Berdasarkan hasil uji coba pada internet dengan kecepatan 20Mbps, bot ini dapat mendapatkan 100 data profil penguna Facebook dalam waktu \pm 20 menit.
\end{abstract}

\begin{tabular}{|c|c|}
\hline & ABSTRACT \\
\hline Keyword: & This research discusses the implementation of semantic analysis on the webdriver to get Facebook user \\
\hline Semantic Analysis & profile data automatically. In this digital era, data has become invaluable. Data can be utilized for everyday \\
\hline Webdriver & applications such as in education, economics and business among many other industries. Facebook is a \\
\hline Facebook Bot & $\begin{array}{l}\text { storage place for large amounts of data. But, retrieving profile data from Facebook is a complicated } \\
\text { endeavor. Therefore, unique methods must be engineered within the bot processes. These countermeasures }\end{array}$ \\
\hline DOJ & $\begin{array}{l}\text { swiftly browse, retrieve user profile data, and group them based on profile categories. This technique uses } \\
\text { the webdriver to create the bot by implementing semantic analysis }\end{array}$ \\
\hline 10.35891/explorit.v\%vi\%i.2283 & $\begin{array}{l}\text { We begin by studying the HTML structure on any given Facebook page to determine the pattern of profile } \\
\text { data. Then the Bot will be developed so that it can open the user's profile page, retrieve profile data and then } \\
\text { analyze it based on the patterns on the HTML structure of the page. With download speeds of } 20 \mathrm{Mbps} \text {, test } \\
\text { results indicate this bot is capable of extracting } 100 \text { Facebook user profiles in approximately } 20 \text { minutes }\end{array}$ \\
\hline
\end{tabular}

@ 2020 diterbitkan oleh Prodi Teknik Informatika Universitas Yudharta Pasuruan

\section{Pendahuluan}

Keberadaan data menjadi sangat berharga pada era ini. Hal ini karena dengan pengolahan data dapat diperoleh pengetahuan baru yang bisa digunakan untuk banyak hal seperti penelitian, memprediksi harga saham, melihat ketertarikan pembeli, analisa sentimen dan lain-lain. Proses tersebut biasa disebut dengan data mining. Data mining adalah proses untuk mengubah sesuatu yang tidak bermanfaat menjadi sesuatu yang berharga dan dapat memberikan suatu informasi yang penting[1]. Salah satu tempat yang menyimpan data penting dalam jumlah besar adalah sosial media seperti Facebook. Tapi tidak mudah untuk mendapatkan dari situs tersebut. Karena facebook tidak mengizinkan bot penjelajah otomatis untuk mengakses halamannya. Maka dari itu butuh tool seperti webdriver untuk mendapatkan data pengguna Facebook secara otomatis dan analisa semantik untuk mengolah dan mengelompokkan data pengguna pada kategori profil seperti pendidikan, alamat, link media sosial, no telepon, whatsapps dan lain-lain. Jadi dengan teknik ini pengambilan data pengguna dari situs Facebook bisa lebih cepat dan akurat.

Semantik bertujuan untuk menerjemahkan kalimat menjadi bentuk representasi lain[2]. Sedangkan teknik yang digunakan untuk mengekstraksi data HTML pada halaman Facebook adalah Regular Expression. Regular Expression berfungsi adalah teknik yang dominan digunakan untuk mengekstrak informasi saat ini[3].

\section{Kajian Teori}

a. Web Semantik

Dalam dunia teknologi informasi penggunaan Word Wide Web (WWW) sangat banyak digunakan untuk mencari informasi berdasarkan metadata, dalam pencarian metadata tersebut lebih dikenal dengan WEB Semantik dimana metode tersebut adalah sebuah kumpulan teknologi dalam dunia 
komputer yang mampu membedakan sebuah informasi yang berlandaskan pada metadata. Hal ini diharapkan dapat membantu pengguna dalam melakuka pencarian informasi secara cepat dan akurat[4].

b. Arsitektur Web Semantik

1). RDF (Resource Description Framework)

Sumber informasi yang didapatkan dan sebuah web baik itu biodata, tenpat maupun sebuah dokumen dan data lainnya sehingga peng gunaan URI (Iniform Resource Identifier) sebagai alat untuk mengindntifikasi secara unik dalam membedakan sebuah resource. Agar penggunaan sumber daya sebuah web (Web Resource) mampu dideskripsikan secara jelas, maka direkomendasikanlah sebuah bahasa RDF (Resource Description Framework) oleh lembaga Word Wide Web Consortium / W3C sebagai standart dalam mendeskripsikan sebuah web resource [2].

\section{2). OWL (Web Ontology Language)}

OWL merupakan salah satu bahasaya yang telah direkomendasi oleh lembaga W3C, dimana bahasa tersebut merupakan bahasa ontologi yang paling ekspresif diguanakn dalam sebuah aplikasi semantik web yang digunakan untuk mereperesentasi sebuah arti dari sebuah terminologi-terminologi pada sebuah pengetahun dimana relasi pada terminolgi tersbut tidak bisa dipisah dari doumen dan aplikasi web. Penggunaan OWL dimaksudkan untuk melakukan sebuah representasi makna dari sebuah kosa kata serta sebuah relasi antara kata dengan kata yang lain sehingga dapat menghasilkan sebuah informasi yang eksplisit. Pembuatan OWL dibentuk dari penggabungan RDF dan RDFS dan ditambahkan vocabulary agar sebuah classes, properties serta indivisuals dapat didefinisikan. OWL memberikan pilihan sub bahasa yang dapat digunakan sesuai dengan kebutuhan, diaman pilihan tersebut adalah OWL Lite, OWL DL, serta OWL FULL[5].

3). SPARQL (SPARQL Protocol and RDF Query Language)

Selain RDF dan OWL W3C juga membuat senuah standart tentang penggunaan query dalam memperoleh data dari web resource, dimana standart tersebut dinamakan SPARQL (SPARQL Protocol and RDF Query Language). SPARQL Query memiliki triple pattern yaitu Subjek, predikat serta objek diman dari masing-masing kriteria tersebut dpat dijadikan sebuah variabel dalam penggunaan SPARQL. Penggunaan Query SPARQL berdasarkan kepada proses mencocokkan sebuah pola triple pada RDF, ada beberapa sintax yang dapat digunakan pada query SPRQL diantaranya adalah :

\section{a) PREFIX Statemen PREFIX}

Adalah sebuah cara menunjukkan informasi yang ada dalam sebuah resource dimana carai ini diwakili oleh URI (Uniform Resource Identifier), pada intinya PREFIX ini diginakan untuk membuat simple sebuah sumber data.

b) SELECT Statement SELECT

Pendefiniasian sebuah variabel dimana hasil nya akan dikembalikan sebagai hasil proses query, Setiap variabel diawali dengan notasi "?". c) WHERE

Pengguaan WHERE digunakan untuk mendefiniskan sejumlah pattern yang wajib dimiliki dari setiap proses query. Semua pola yang mewakili sebuah kalimat RDF harus sesuai dengan RDF Triple yang terdiri dari sebuah subjek, predikat, dan objek. RDF triple tersebut dapat direpresentasikan oleh URI atau sebuah variable dan nilai literal.

\section{Metodologi Penelitian}

Metode penelitian yang digunakan dalam penelitian ini adalah Research and Development (R\&D)

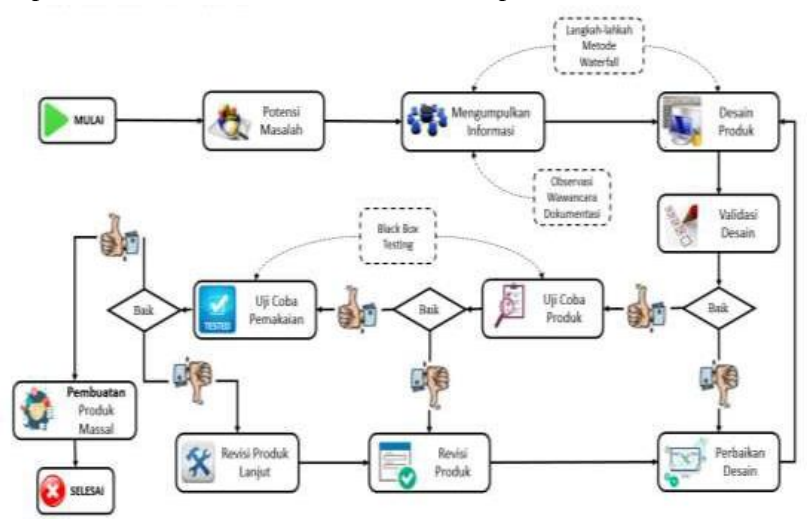

Gambar 1. Bagan Penelitian R\&D

[Sumber: google.com]

a. Potensi dan Masalah

Untuk mendapatkan sebuah permasalahan yang terjadi perlu dilakukannya sebuah penelitian awal. Hal ini dilakukan untuk mendapatkan informasi dan pengumpulan data serta mecari referensi yang tepat untuk mendukung dari sebuah penelitan

b. Mengumpulkan Informasi

Proses pengumpulan data dilakukan dengan cara melakukan uji coba pencarian data tanpa menggunan menggunakan metode semantik. Peran ketua pengusul pada tahap ini adalah mencari sumber referensi tentang penggunaan semantik dan Webdriver Selenium. Sedangkan untuk anggota pengusul melakukan beberapa uji coba pencarian tanpa menggunakan metode semantik dan Webdriver Selenium

c. Desain Produk

Proses ini dilakukan setelah proses pengumpulan data dilakukan, hal ini dilakukan untuk mempermudah dalam proses pengembangan aplikasi, pada proses ini ketua pengusul melakukan desain sistem, sedangkan anggota pengusul memberikan informasi terkait hasil uji coba pencarian untuk dijadikan acuan.

d. Validasi Desain 
Untuk mengatahui kesesuaian sebuah desain sistem maka perlu dilakukan validasi desain dengan aplikasi yang telah dihasilkan. ketua pengusul mengemukan hasil rancangan desain dan aplikasi sedangkan anggota pengusul memberikan masukan sesuai dengan hasil. Langkah ini dilakukan untuk mevalidasi desain dan aplikasi agar siap diterapkan.

e. Perbaikan Desain

Proses perbaikan desain dilakukan untuk menghasilkan desain yang lebih sempurna, proses ini dilakukan mengacu kepada hasil validasi desai yang telah dilakukan.

f. Uji Coba Produk

Setelah desain dan aplikasi selasai dibuat maka perlu ada proses uji coba produk untuk mengetahui kesesuaian aplikasi denga kebutuhan, pada proses ini ketua pengsul melakukan uji coba pencarian dengan menggunakan metode semantic, sedangkan anggota pengusul melakukan dokumentasi dari hasil percobaan.

g. Revisi Produk

Revisi produk dilakuakn apabila dalam tahapan uji coba mengalami ketidaksesuain dengan sistem, revisi ini dilakukan dengan mengacu kepada hasil dokuntasi uji coba.

h. Uji Coba Pemakaian

Proses pengujian ini dilakukan dengan sistem black box testing. Menurut Nidhra dan Dondeti black box testing juga disebut functional testing, sebuah teknik pengujian fungsional yang merancang test case berdasarkan informasi dari spesifikasi[6]

Pada proses ini ketua pengusul membuat draf kuisioner untuk untuk diberikan kepada masyarakat, sedangkan anggota pengusul membantu ketua dalam penyebarang kuisioner

i. $\quad$ Revisi Produk Lanjut

Pada proses ini dilakukan proses perbaikan yang mengacu pada hasil kuisioner yang telah direkap oleh anggota pengusul, yang kemudian akan dijadikan acuan oleh ketua pengusul dalam melakukan perbaikan sistem dan aplikasi.

j. Pembuatan Produk Masal

Proses ini adalah proses akhir yang dilakukan dalam proses pengembangan aplikasi agar bisa digunakan oleh masyarakat

\section{Hasil Uji Coba Dan Pembahasan}

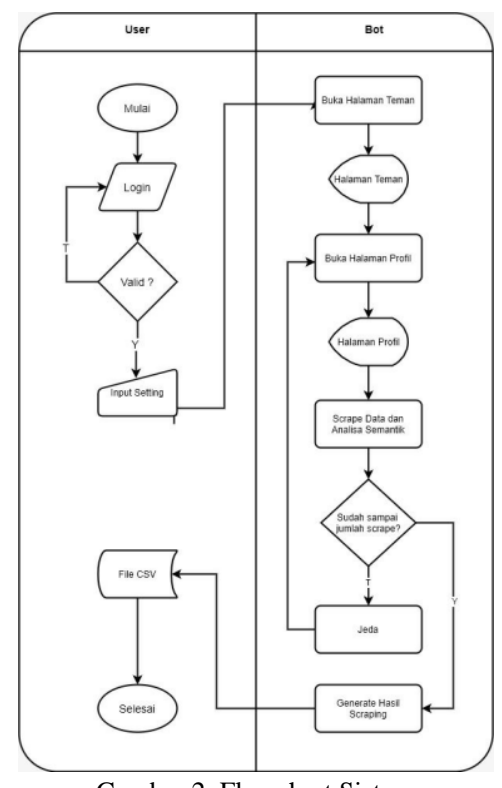

Gambar 2. Flowchart Sistem

Dalam proses ekstraksi data profil pengguna Facebook, Kami menggunakan analisa semantik untuk mengenali kategori profil pengguna. Hal ini dilakukan karena data profil yang ditampilkan di halaman facebook tidak memiliki label kategori seperti data pendidikan. Semantik dapat menyamakan kata-kata atau kalimat yang memiliki makna yang sama meskipun kata-kata atau kalimat tersebut berbeda[7].

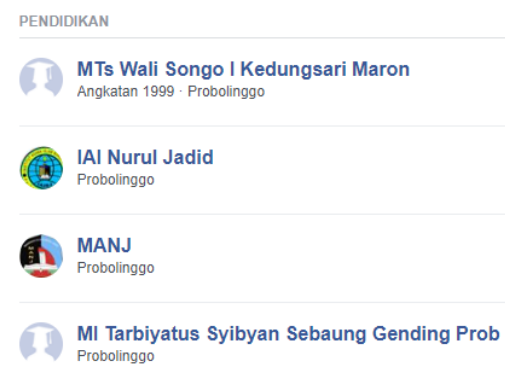


Gambar 3. Halaman Pendidikan Pengguna Facebook

[Sumber: facebook.com]

Pada gambar di atas facebook hanya menampilkan riwayat pendidikan pengguna, tapi tidak disebutkan jenjang pendidikan pada setiap riwayat pendidikan. Dengan semantik, kita bisa mengetahui jenjang setiap pendidikan hanya dari nama instansi pendidikan tersebut. Analisa semantik mengenali makna dari kata/kalimat berdasarkan pola. Pola dapat diketahui dengan menganalisa struktur HTML pada halaman Facebook. Contoh, jika pada jenjang pendidikan terdapat kata SMA, MA, SMK dan kata yang berkaitan dengan 3 kata tersebut seperti "Sekolah Menengah Atas", maka Riwayat pendidikan tersebut akan diberi masukkan ke jenjang pendidikan menengah atas.

Bot dikembangkan menggunakan bahasa pemrograman Java dan plugin Selenium Webdriver. Plugin ini bisa digunakan untuk membuat otomatisasi browser yang tangguh, terukur dan dapat didistribusikan ke banyak lingkungan sistem[8]. Adapun tampilan dari Bot adalah seperti gambar 3.

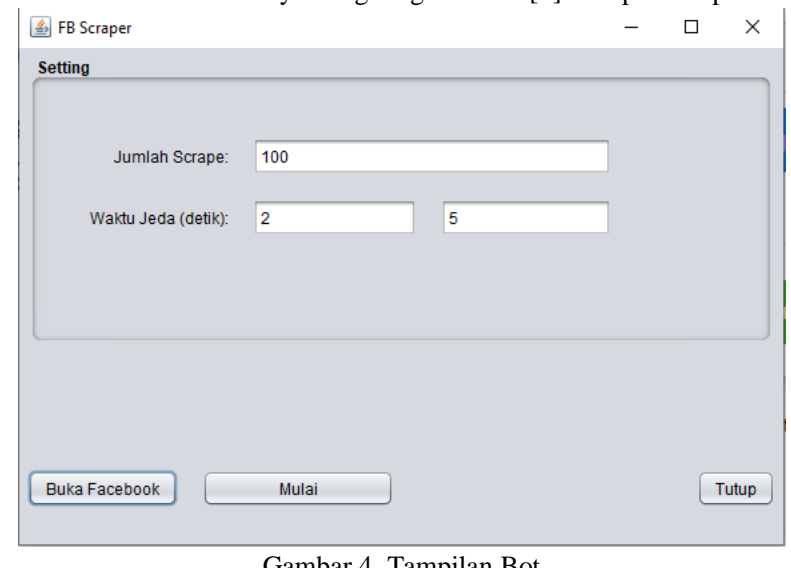

Gambar 4. Tampilan Bot

Pada Bot terdapat 2 setting yang harus di isi, pertama jumlah scrape dan waktu jeda. Waktu jeda ini bersifat acak antara waktu minimum dan maksimum. Hal ini digunakan untuk mengelabui bot detector milik Facebook dengan membuat bot ini berperilaku seolah-olah manusia. Setelah itu, pengguna user bisa menekan tombol "Buka Facebook" untuk membuka halaman login Facebook dan User akan diminta login secara manual. Selanjutnya user dapat menekan tombol "Mulai" untuk memulai proses scraping. Adapun tahapan proses scraping adalah sebagai berikut :

1. Bot akan membuka halaman daftar teman

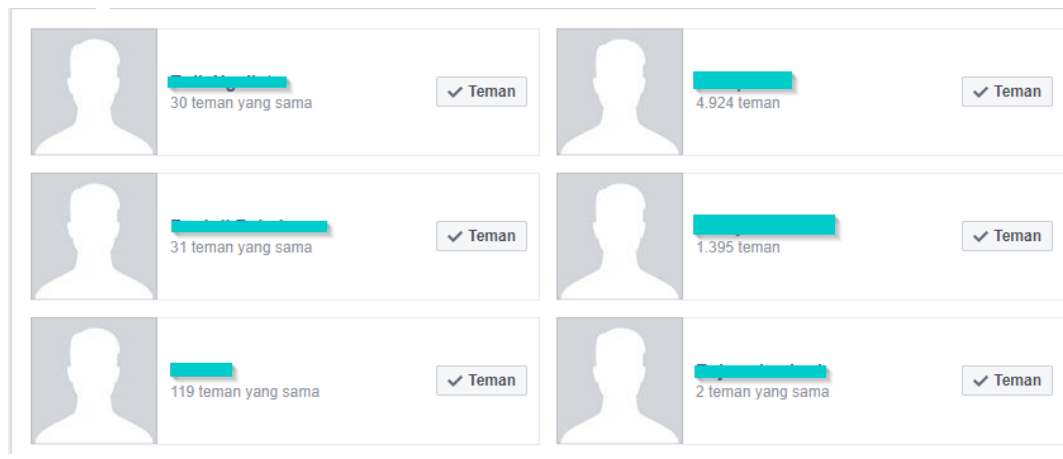

Gambar 5. Halaman Daftar Teman Facebook

2. Pada halaman daftar teman, Bot akan membuka halaman profil setiap teman facebook satu-persatu

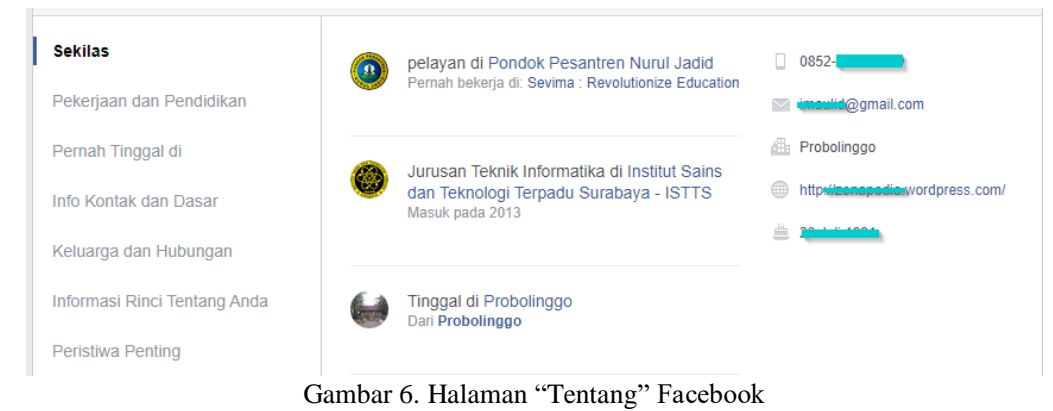

3. Bot akan mengambil data profil teman facebook dan mengelompokkan data tersebut menggunakan metode Analisa Semantik (Regular Expression)

Adapun hasil dari scraping bot ini adalah berupa file CSV yang berisi data profil pengguna Facebook yang sudah dikelompokkan ke dalam kolomkolom. 
Tabel 1 : Data Hasil Scraping

\begin{tabular}{|c|c|c|c|c|c|}
\hline Nama User & Jenis Kelamin & Riwayat Pekerjaan & Dasar & Menengah Pertama & Menengah Atas \\
\hline Mahmud & Laki-laki & $\begin{array}{l}\text { Guru di SMP } 1 \text { Probolinggo, } \\
\text { Programmer di PT Jaya Makmur }\end{array}$ & - & SMP NJ & SMK NJ \\
\hline Siti & Perempuan & $\begin{array}{l}\text { Admin di Toko ABC, Owner TOKO } \\
X Y Z\end{array}$ & SD Negeri 1 Kraksaan & MTs NJ & MA Nurul Jadid \\
\hline Rudianto & Laki-laki & Pelajar & - & MTs Miftahul Huda & SMK 2 Probolinggo \\
\hline M. Fajar & Laki-laki & Setia Mencari Cinta & - & SMP NJ & SMA Nurul Jadid \\
\hline
\end{tabular}

Tabel 1 : Data Hasil Scraping (Lanjutan)

\begin{tabular}{|l|l|l|l|l|}
\hline Perguruan Tinggi & No Telp & Alamat & Kepercayaan & Bahasa \\
\hline & & & & \\
UNUJA & & & & \\
\hline & 085234124865 & Probolinggo & Islam & Jawa, Indonesia \\
\hline UNUJA & & & & \\
\hline UNUJA & 085234125462 & Surabaya & Islam & Madura, Indonesia \\
\hline- & 085264532569 & Kraksaan & Islam moderat & Madura, Indonesia \\
\hline
\end{tabular}

\section{Kesimpulan}

Berdasarkan hasil uji coba pada internet dengan kecepatan 20Mbps, Bot ini dapat mendapatkan 100 data profil penguna Facebook dalam waktu \pm 20 menit. Bot ini juga bisa dijalankan secara paralel untuk mendapatkan hasil scraping yang lebih cepat dan singkat. Selain itu, kecepatan internet dan spesifikasi PC yang digunakan akan berpengaruh terhadap kecepatan Bot. Dari hasil uji coba tersebut dapat disimpulkan bahwa Bot ini bisa mendapatkan data profil pengguna Facebook dalam jumlah banyak dengan waktu yang relatif singkat. Selain itu, Bot ini juga bisa mengelompokkan data tersebut berdasarkan kategori profil seperti pendidikan.

\section{Daftar Pustaka}

[1] S. Rizal, P. Studi, T. Informatika, and U. Yudharta, "Penerapan Algoritma Naïve Bayes Untuk Prediksi Penerimaan Siswa Baru Di Smk AlAmien Wonorejo," Explor. IT J. Keilmuan dan Apl. Tek. Inform., vol. 10, no. 1, pp. 14-21, 2018, doi: 10.35891/explorit.v10i1.1671.

[2] J. Suciadi, "Studi Analisis Metode-Metode Parsing Dan Interpretasi Semantik Pada Natural Language Processing," J. Inform., vol. 2, no. 1, pp. 22-22, 2001, doi: 10.9744/informatika.2.1.pp.13-22.

[3] Y. Li, R. Krishnamurthy, S. Raghavan, S. Vaithyanathan, and H. V. Jagadish, "Regular expression learning for information extraction," EMNLP 2008 - 2008 Conf. Empir. Methods Nat. Lang. Process. Proc. Conf. A Meet. SIGDAT, a Spec. Interes. Gr. ACL, no. October, pp. 21-30, 2008, doi: 10.3115/1613715.1613719.

[4] M. Unik and M. Ramli, "Penerapan Metode Semantik Search Dalam Sistem Informasi Pencarian Dokumen Kerja Praktek Dan Skripsi Berbasis Web," Rabit J. Teknol. dan Sist. Inf. Univrab, vol. 3, no. 2, pp. 83-88, 2018, doi: 10.36341/rabit.v3i2.480.

[5] Y. F. Badron, F. Agus, and H. R. Hatta, "STUDI TENTANG PEMODELAN ONTOLOGI WEB SEMANTIK DAN PROSPEK PENERAPAN PADA BIBLIOGRAFI ARTIKEL JURNAL ILMIAH,” Pros. Semin. Ilmu Komput. dan Teknol. Inf., vol. 4, no. 1, pp. 23385081, 2017, [Online]. Available: http://journal.student.uny.ac.id/ojs/ojs/index.php/pgsd/article/viewFile/135/130.

[6] S. Nidhra, "Black Box and White Box Testing Techniques - A Literature Review," Int. J. Embed. Syst. Appl., vol. 2, no. 2, pp. 29-50, 2012, doi: 10.5121/ijesa.2012.2204.

[7] N. Riza Akbar, R. Faisal, and H. Budi, "Pengembangan Data Uji Sistem Komputasi Kemiripan Teks Secara Semantik Berbahasa Indonesia," Semin. Inform. Apl. Polinema, 2016.

[8] Anonymous, "Selenium WebDriver. Internet: https://www.selenium.dev, 03 September 2020". 
Maulidiansyah, dkk./Explore IT 12 (2) 2020 pp. 81-86 